\title{
Hepatocellular carcinoma in Australia's Northern Territory: high incidence and poor outcome
}

\section{Christopher Parker \\ Bachelor of Medical Science Student, Global and Tropical Health Division? \\ Steven Y C Tong \\ MBBS, FRACP, PhD \\ Senior Research Fellow, \\ Global and Tropical Health Division \\ Karen Dempsey BSc, MAE \\ Senior Epidemiologist ${ }^{2}$ \\ John Condon MBBS, FAFPHM, PhD Principal Research Fellow, Epidemiology and Health Systems Division \\ Suresh K Sharma Hepatology Clinical Nurse Consultant ${ }^{3}$ \\ John W C Chen MBBS, FRACS, PhD Hepatobiliary Surgeon \\ William Sievert MD, FRACP Director, Department of Gastroenterology and Hepatology 5 \\ Joshua S Davis MBBS, FRACP, PhD Senior Research Fellow, Global and Tropical Health Division? \\ 1 Menzies School of Health Research, Darwin, NT. \\ 2 Health Gains Planning Unit, Northern Territory Government, Darwin, NT. \\ 3 Royal Darwin Hospital, Darwin, NT. \\ 4 South Australian Live Transplant Unit, Flinders Medical Centre Adelaide, SA. \\ 5 Monash Medical Centre Melbourne, VIC. \\ joshua.davis@ menzies.edu.au}

MJA 2014; 201: 470-474 doi: 10.5694/mjal3.11ו17 epatocellular carcinoma (HCC) is a devastating complication of chronic viral hepatitis. It is the fifth most common incident cancer in the world, and the second most common cause of cancer death. ${ }^{1,2} \mathrm{HCC}$ is among the fastest growing causes of cancer incidence and mortality in Australia, 3,4 but its epidemiology in northern Australia has not been comprehensively described, and there are no published analyses from the past decade. Past reports of the incidence of $\mathrm{HCC}$ in the Northern Territory have shown it to be higher than the national level and 6-10 times higher among Indigenous Australians than non-Indigenous Australians. 5,6 However, previous studies have been based only on registry data and have not described the clinical features and management of HCC in the NT.

The NT has a population of about 230000 people, of whom $30 \%$ are Indigenous. Indigenous Australians have higher rates of chronic hepatitis $B$ virus (HBV) infection than the general Australian population. Recent NT studies have found seroprevalence estimates for hepatitis B surface antigen (HBsAg) in adults of 3\%-12\%,,-11 compared with $1.0 \%$ for Australia as a whole. ${ }^{12}$ The NT also presents challenges of remoteness and cultural and linguistic barriers, making HCC surveillance and treatment problematic. A universal program of vaccinating infants against HBV has been in place in the NT since 1990, and although this has resulted in a falling prevalence of HBV infection, ${ }^{7}$ it is unclear if there has been any impact on the incidence of HCC thus far.

We aimed to determine the incidence of HCC in the NT over the past two decades and to describe the clinical and demographic features, management and outcomes of HCC among patients in the Top End of the NT over the past decade. Since some patients had their management coordinated through a centralised liver

Abstract

Objective: To describe the epidemiology, clinical features, management and outcomes of hepatocellular carcinoma (HCC) in the Northern Territory over the past decade.

Design, setting and patients: An NT-wide epidemiology study covering the period 1991-2010 and a clinical cohort study including patients diagnosed during 2000-2011. HCC diagnoses were provided by the NT Cancer Registry and crosschecked against clinical records.

Main outcome measures: Age-adjusted incidence of HCC; management; clinical features; and median and 1-year survival.

Results: There were 145 incident cases of HCC in the NT during 1991-2010, giving an age-adjusted annual incidence of $22.7 / 100000(95 \% \mathrm{Cl}, 17.2-26.8)$ for Indigenous Australians and 4.0/100 000 (95\% Cl, 2.1-5.8) for non-Indigenous Australians - an incidence rate ratio of $5.9(95 \% \mathrm{Cl}, 4.7-7.4)$. There was no significant change in annual age-adjusted incidence over this period. The most common causative factors were hepatitis B virus in Indigenous people and hepatitis $C$ virus in non-Indigenous people. Most people were diagnosed late, only 13/80 were diagnosed by screening, and outcomes were poor, with 28/80 overall surviving to 1 year. Outcomes were better among those managed through a centralised multidisciplinary service than among those who were not (adjusted hazard ratio for death at 1 year, 0.35 [95\% Cl, 0.16-0.81]).

Conclusion: HCC incidence remains high in the Indigenous people of the NT. More resources are needed for HCC surveillance and management programs in this population.

clinic, we also aimed to explore the effect of site of care and Indigenous status on management and outcomes.

\section{Methods}

The study was approved by the Human Research Ethics Committee of the NT Department of Health and Menzies School of Health Research. We conducted this study in two parts: an NT-wide epidemiology study, and a retrospective cohort study including patients only from the Top End.

\section{NT-wide epidemiology study}

Data regarding all cases of HCC diagnosed among NT residents during 1991-2010 were supplied by the NT Cancer Registry, which routinely collects HCC notifications by three methods: histology reports, hospital discharge coding and death certificates. All cases from the NT Cancer Registry were cross-checked against hospital records to confirm the diagnosis. The diagnosis of HCC was defined according to the criteria proposed by the American Association for the Study of Liver Diseases. ${ }^{13}$ These criteria rely primarily on imaging findings; specifically, tumour size and appearance, and contrast enhancement characteristics.

Population denominator data were derived from the Australian Bureau of Statistics and the NT Government's Health Gains Planning Branch. ${ }^{14}$ Agestandardised incidence was calculated using the direct method, with 5-year age brackets and the year 2001 Australian standard population..$^{15}$ The estimated resident population (ERP) for the midpoint of each time period used in the analysis was used as the denominator when calculating rates (eg, the 2000 ERP for the period 1991-2010, the 1993 ERP for 1991-1995).

\section{Clinical retrospective cohort study}

Detailed clinical data were collected on all patients who were resident in the Top End of the NT and were diagnosed with HCC from 1 January 2000 to 30 June 2011. This part of the study was restricted to the Top End (Darwin urban, Darwin rural, East Arnhem 
and Katherine administrative regions), as it is the referral base for the Royal Darwin Hospital (RDH), where we had access to medical records and hospital databases. The patients were identified by three overlapping methods: a prospective register kept by RDH liver clinic (2007-2011), hospital discharge coding (International Classification of Diseases, 10th revision, codes C22.0 and C22.9) and the NT Cancer Registry. For each patient, clinical and demographic data were collected from paper medical records and hospital pathology and radiology databases. Mortality data were collected from the NT Government's client master index, which has recorded all deaths of NT residents occurring in the NT since 1995.

In 2006, a public liver clinic began operating at $\mathrm{RDH}$, coordinating the diagnosis and management of HCC patients in the Top End using multidisciplinary input from Flinders Medical Centre in Adelaide. Before this, HCC patients were cared for by general surgery, oncology, general medicine or a private liver clinic. Even after 2006, not all HCC patients were managed through the RDH liver clinic. Hence, for the purposes of analysis of management and outcomes, we divided the study a priori into two periods (2000-2005 and 2006-2011), and within the second period divided patients into those managed through the RDH liver clinic and those managed by other medical practitioners. There is no coordinated program of HCC surveillance in the NT, but patients referred to the RDH liver clinic are offered HCC surveillance comprising a 6-monthly ultrasound scan and test for serum alpha-fetoprotein (AFP) level if they have cirrhosis or if they are high-risk and non-cirrhotic, as per international guidelines. ${ }^{13}$

\section{Data management and statistical methods}

Clinical data were collected on paper case-record forms by a trained data collector, and all forms were checked by a liver clinic specialist before data entry. Data were entered into an Access database (Version 12, Microsoft) and were analysed using Stata version 11 (StataCorp). Normally distributed continuous variables were described using mean and standard deviation, and were compared using the Student $t$ test. Non-normally distributed continuous variables were described using median and interquartile range (IQR) and compared using the MannWhitney $U$ test. The $\chi^{2}$ or Fisher exact tests were used when comparing categorical data between two groups. Incidence rates were compared by 5-year blocks and Indigenous status using Poisson regression. KaplanMeier survival curves were compared using the log-rank test. A two-sided $P$ of less than 0.05 was considered statistically significant. Among patients with chronic HBV infection, individual annual risk of HCC was estimated by dividing the age-specific crude incidence rate by the seroprevalence of HBsAg and multiplying the result by the proportion of HCC attributable to HBV in the whole cohort. Cox proportional hazards models examining the first 12 months of follow-up were used for multivariate models of survival, with all-cause mortality as the outcome.

\section{Results}

\section{Incidence of HCC in the NT, 1991- 2010}

There were 145 incident cases of HCC in the NT over this 20-year period (Appendix 1; online at mja.com. $\mathrm{au}$ ), giving an age-adjusted annual incidence of 22.7/100000 (95\% CI, $17.2-26.8$ per 100000) for Indigenous Australians and 4.0/100000 (95\% CI, 2.1-5.8 per 100000) for non-Indigenous Australians - an incidence rate ratio of 5.9 (95\% CI, 4.7-7.4). Appendix 2 (online at mja.com.au) shows the age-adjusted incidence for 2006-2010 compared with rates for comparable periods for Australia as a whole and other countries.

Crude incidence rates were steady over the first 15 years, but rose significantly in the last 5 years of the study period, being 3.3/100000/year for the period 1991-1995, 2.7 for 1996-2000, 3.1 for 2001-2005 and 5.5 for 20062010 (crude incident rate ratio for the last 5 years compared with the first 5 years, 1.66 [95\% CI, 1.06-2.51]). However, the annual age-adjusted incidence did not significantly increase over the study period $(10.4,6.1,5.1$
1 Annual incidence of hepatocellular carcinoma in the Top End, Northern Territory, by age group and Indigenous status, 2001-2010*

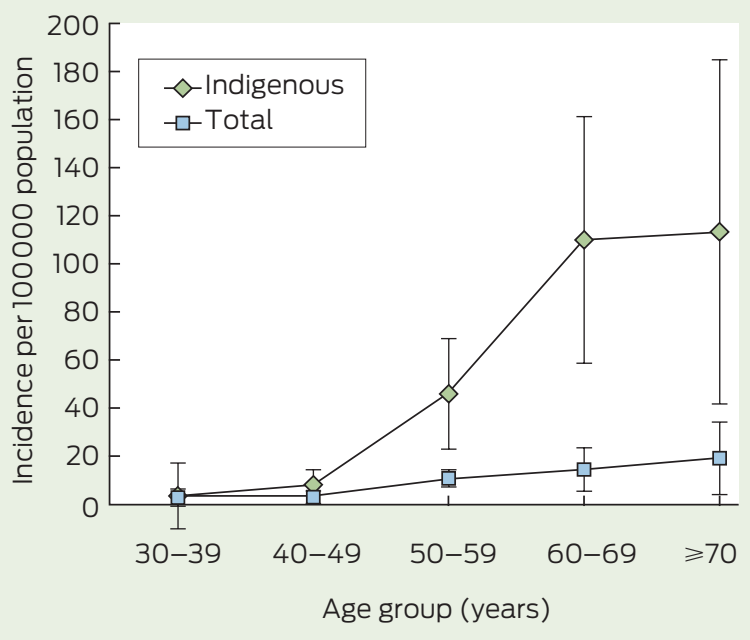

*Error bars represent 95\% confidence intervals.

and 7.8/100000, respectively, for the four 5 -year blocks as above).

The incidence was lowest among patients aged under 40 years and increased sharply among those aged over 50 years, to a greater extent for Indigenous people than non-Indigenous people (Box 1). Assuming that the seroprevalence of chronic HBV in Indigenous people over 40 years is $8 \%{ }^{8-10}$ and that $60 \%$ of HCC is attributable to $\mathrm{HBV}$, we estimated the individual annual risk of HCC in $\mathrm{HBV}$-infected Indigenous people to be $0.05 \%$ for ages $40-49$ years, $0.34 \%$ for ages $50-59$ years, $0.83 \%$ for ages $60-69$ years and $0.86 \%$ for ages $70-79$ years.

\section{Demographic and clinical features of HCC in the Top End, 2000-2011}

There were 80 new diagnoses of HCC in the Top End during 2000-2011, of which 37 were in Indigenous people, and 64 were in males (Box 2). Most patients were diagnosed with advanced disease; 13 were detected by screening and 21 were candidates for liver transplantation based on tumour size and number (Milan criteria ${ }^{16}$ ). The most commonly identified aetiological factors were chronic HBV infection among Indigenous people (current infection in 15/37, and current or past infection in 23/37) and $\mathrm{HCV}$ infection among non-Indigenous people (21/43) (Box 2). 


\section{Management and outcomes}

Just over half the patients (42) were managed with palliative treatment only. Of the remaining 38, 12 patients underwent surgical resection, 10 were treated with oral sorafenib, eight had transarterial chemoembolisation, seven had radiofrequency ablation and three underwent liver transplantation (some patients had more than one type of therapy). All patients who were candidates for curative or local ablation therapies were referred to Flinders Medical Centre in Adelaide.

The median time from diagnosis to death was 139 days overall. The median for Indigenous people (64 days) was lower than that for nonIndigenous people (172 days); the difference, although large, did not reach statistical significance $(P=0.07$; Box 3 , A). Although more patients were diagnosed at a potentially curable stage during the second half of this study, outcomes did not significantly improve (Box 4); however, within the second period, those managed by the liver clinic had better outcomes than those who were not $(17 / 26 \mathrm{v} 6 / 30$ alive at 1 year; $P=0.001$; hazard ratio for death, 0.32 [95\% CI, 0.15-0.70]; Box 4 and Box 3, B). Among the small group of patients diagnosed at a potentially curable stage (ie, within the Milan criteria), curative treatment was received by $6 / 12$ patients in the RDH liver clinic group and $0 / 7$ patients managed in other settings $(P=0.02)$.

In a multivariate model controlling for age, sex, Indigenous status and cirrhosis, management through the $\mathrm{RDH}$ liver clinic remained the only significant predictor of survival at 1 year (adjusted hazard ratio, 0.35 [95\% CI, 0.16-0.81]).

\section{Discussion}

Despite the rising incidence of HCC in Australia as a whole, it remains about six times more common among Indigenous people than non-Indigenous people in the NT. The incidence rate for Indigenous people is similar to the relatively high population-wide rate in China. Hepatitis B infection is the most important aetiological factor among Indigenous people, and there was no decrease in HCC incidence or in the proportion of HCC attributable to HBV over the 20-year period after the introduction of universal infant HBV vaccination in the NT. We also found an independent association between management of HCC through a centralised service,

2 Clinical and demographic features of patients in the Top End, Northern Territory, who were diagnosed with hepatocellular carcinoma, 2000-2011

\begin{tabular}{|c|c|c|c|c|}
\hline & All & Indigenous & Non-Indigenous & $P^{*}$ \\
\hline Total no. & 80 & 37 & 43 & \\
\hline Age at diagnosis, years (median [IQR]) & $60.5(53.4-66.4)$ & $63.9(52.9-68.6)$ & $57.9(54.0-64.5)$ & 0.35 \\
\hline Male & 64 & 23 & 41 & $<0.001$ \\
\hline Remote dwelling & 29 & 22 & 7 & $<0.001$ \\
\hline Born overseas & 19 & 0 & 19 & - \\
\hline Symptomatic presentation & 52 & 28 & 24 & 0.14 \\
\hline HCC detected by screening & 13 & 5 & 8 & 0.45 \\
\hline Within transplant criteriat & 21 & 7 & 14 & 0.17 \\
\hline Alpha-fetoprotein $>15 \mathrm{IU} / \mathrm{mL}$ at diagnosis & $42 / 74$ & $18 / 36$ & $24 / 38$ & 0.25 \\
\hline HBV serology positive fई $^{\prime}$ & 38 & 23 & 15 & 0.05 \\
\hline HBsAg positive ${ }^{\S}$ & 22 & 15 & 7 & 0.02 \\
\hline HCV antibody positive ${ }^{\delta}$ & 22 & 1 & 21 & $<0.001$ \\
\hline Cirrhosis & 58 & 21 & 37 & 0.002 \\
\hline Alcoholic cirrhosis ${ }^{\S}$ & 36 & 13 & 23 & 0.88 \\
\hline Tumour number at diagnosis (median [IQR]) & $2(1-4)$ & $2(1-4)$ & $2(1-4)$ & 0.72 \\
\hline $\begin{array}{l}\text { Maximum tumour diameter at diagnosis, } \mathrm{cm} \\
\text { (median }[\mathrm{IQR}] \text { ) }\end{array}$ & $6.2(4.2-8.1)$ & $8.0(5.0-11)$ & $6.0(3.7-7.0)$ & 0.002 \\
\hline
\end{tabular}

$\mathrm{HBsAg}=$ hepatitis B surface antigen. $\mathrm{HBV}=$ hepatitis $\mathrm{B}$ virus. $\mathrm{HCC}=$ hepatocellular carcinoma. $\mathrm{HCV}=$ hepatitis $\mathrm{C}$ virus. $\mathrm{IQR}=$ interquartile range. $*$ Comparing Indigenous and non-Indigenous groups. $†$ Milan criteria determining suitability for cure by liver transplantation.16 $¥$ Includes both core antibody and surface antigen (ie, past or present infection). § Potential aetiological factors (alcohol, HBV and HCV) are not mutually exclusive. in close liaison with a referral centre and coordinated care, and improved outcomes that were not explained by differences in the period, patient demographics or comorbidities.

Although the RDH is geographically isolated and is not a liver transplant centre, the outcomes we report are similar to those from comparable urban health care systems, although they are inferior to those from highly selected case series in quaternary referral centres (Appendix 3; online at mja.com.au).

International guidelines recommend 6-monthly surveillance for HCC $^{17,18}$ using liver ultrasound in selected high-risk people, and this has been shown to improve outcomes, ${ }^{19}$ and to be cost-effective if the individual risk of $\mathrm{HCC}$ exceeds $0.2 \%$ per year. ${ }^{13}$ However, there are no specific recommendations for screening Indigenous Australians with HBV infection. Our study shows that the incidence of HCC is particularly high among Indigenous people once they pass the age of 50 years. The estimated individual annual risk, which rose from $0.34 \%$ for 50 -59-year-olds to $0.86 \%$ for $70-79$-year-olds, justifies a call for HCC surveillance in all Indigenous Australians with HBV infection from the age of 50 years.

The improved outcomes in patients managed through the RDH liver clinic may be partly attributable to earlier diagnosis and, thus, less advanced disease. However, even within the small group of patients diagnosed at a potentially curable stage, more patients received curative treatment in the $\mathrm{RDH}$ liver clinic group.

That there has as yet been no observable effect of the HBV vaccination program on HCC incidence does not imply that it is ineffective, but rather, that it has only recently been introduced, since most people diagnosed with HCC are over 50 years of age. HCC incidence in China and Alaska, where vaccination programs have been in place for longer, has already started to decrease. ${ }^{20,21}$ Since there is a large pool of people born before 1990 who have HBV infection, and a significant proportion of $\mathrm{HCC}$ is caused by factors other than HBV, HCC will continue to be an important public health problem in the NT for decades. 
3 Kaplan-Meier survival curves comparing Indigenous and non-Indigenous patients diagnosed with hepatocellular carcinoma, 2000-2011 (A) and patients who did or did not receive centrally coordinated care through the liver clinic during 2006-2011 (B)
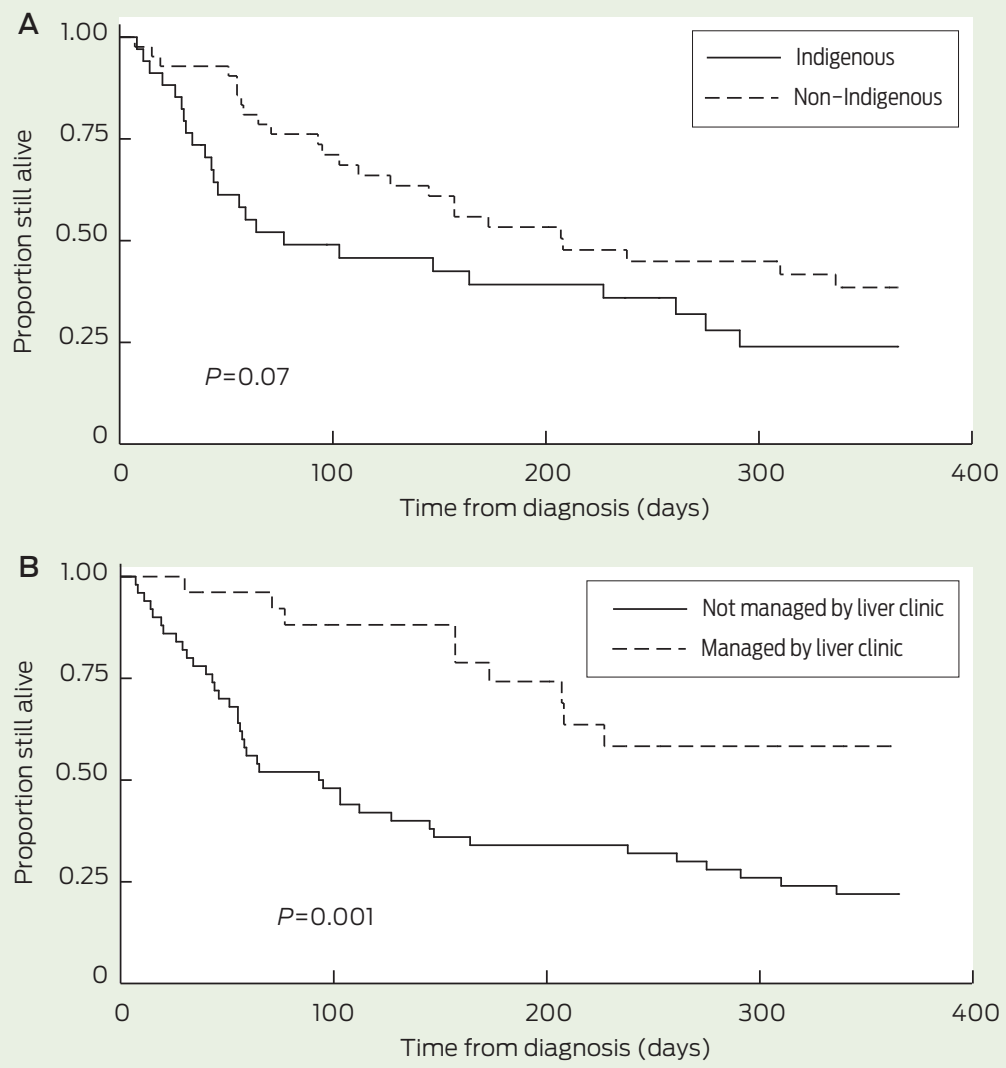

Ultrasound scanning is not available in most remote NT communities. Since about $60 \%$ of Indigenous patients in this cohort came from remote communities, any HCC surveillance program must include strategies to overcome this barrier. Although there are many competing priorities in Indigenous health care in the NT, we believe the high incidence of and mortality from HCC justify the consideration of an appropriately resourced surveillance program including outreach sonography services. HBV case finding and antiviral treatment have been shown to be cost-effective for preventing HCC in high-risk populations, ${ }^{22}$ so resources to reduce the impact of HCC should be broadly directed at HBV screening and treatment as well as HCC surveillance.

In conclusion, both incidence of and mortality from HCC remain unacceptably high among Indigenous people in the NT, but outcomes can be improved if tumours are diagnosed at an early and treatable stage and care is coordinated through a centralised service. Furthermore, Indigenous people aged over 50 years should be added to the previously designated groups at higher risk of HCC for whom surveillance is recommended.

\begin{tabular}{|c|c|c|c|c|c|c|}
\hline & $\begin{array}{l}\text { All patients } \\
2000-2005\end{array}$ & $\begin{array}{l}\text { All patients } \\
2006-2011\end{array}$ & $P^{*}$ & $\begin{array}{l}\text { Managed by RDH liver } \\
\text { clinic 2006-2011 }\end{array}$ & $\begin{array}{l}\text { Not managed by RDH } \\
\text { liver clinic 2006-2011 }\end{array}$ & $P^{\dagger}$ \\
\hline Total no. & 24 & 56 & & 26 & 30 & \\
\hline Indigenous & 13 & 24 & 0.35 & 8 & 16 & 0.09 \\
\hline $\begin{array}{l}\text { Age at diagnosis, years } \\
\text { (median [IQR]) }\end{array}$ & $51.5(40.2-68.3)$ & $58.4(54.2-66.0)$ & 0.90 & $57.0(54.3-64.5)$ & $61.0(54.0-69.4)$ & 0.17 \\
\hline Cirrhosis & 15 & 43 & 0.15 & 23 & 20 & 0.08 \\
\hline Diagnosed by screening & 0 & 13 & 0.01 & 11 & 2 & 0.003 \\
\hline Within transplant criteria $\ddagger$ & 2 & 19 & 0.02 & 12 & 7 & 0.07 \\
\hline $\begin{array}{l}\text { Maximum tumour diameter at } \\
\text { diagnosis, } \mathrm{cm} \text { (median [IQR]) }\end{array}$ & $7.0(6.0-9.0)$ & $6.0(3.7-8.1)$ & 0.47 & $4.75(2.9-6.8)$ & $7.5(5.0-8.3)$ & 0.06 \\
\hline HBV serology positive ${ }^{\varsigma}$ & 9 & 29 & 0.24 & 13 & 16 & 0.80 \\
\hline HBsAg positive & 5 & 17 & 0.38 & 8 & 14 & 0.22 \\
\hline HCV antibody positive & 2 & 20 & 0.01 & 11 & 9 & 0.39 \\
\hline $\begin{array}{l}\text { Received potentially curative } \\
\text { therapy' }\end{array}$ & 7 & 12 & 0.46 & 9 & 3 & 0.03 \\
\hline Alive at 1 year & 5 & 23 & 0.10 & 17 & 6 & 0.001 \\
\hline
\end{tabular}


Acknowledgements: We thank Libby John, Darren Mounkley, Ramon Pathi and Mark Brooke-Smith from Flinders Medical Centre; and Krispin Hajkowicz, Jane Davies and all the registrars from the Royal Darwin Hospital liver clinic for helping with clinical management of the patients in this study. We thank Mark Loewenthal for statistical advice. National Health and Medical Research Council early career fellowships provided salary support for Joshua Davis and Steven Tong.

Competing interests: No relevant disclosures.

Received 27 Aug 2013, accepted 24 Feb 2014

1 Parkin DM, Bray F, Ferlay J, Pisani P. Global cancer statistics, 2002. CA Cancer J Clin 2005; 55: 74-108.

2 International Agency for Research on Cancer, World Health Organization. GLOBOCAN 2012: estimated cancer incidence, mortality and prevalence worldwide in 2012. Liver cancer. http://globocan.iarc.fr/Pages/fact_sheets_ cancer.aspx (accessed Jan 2014).

3 Australian Institute of Health and Welfare. Cancer in Australia 2010: an overview. Canberra: AlHW, 2010. (AlHW Cat. No. CAN 56; Cancer Series No. 60.) https://www.aihw.gov.au/ publication-detail/?id=6442472459 (accessed Feb 2014).

4 MacLachlan JH, Cowie BC. Liver cancer is the fastest increasing cause of cancer death in Australians. Med J Aust 2012; 197: 492-493.

5 Wan X, Mathews JD. Primary hepatocellular carcinoma in Aboriginal Australians. Aust J Public Health 1994; 18: 286-290.

6 Condon JR, Barnes T, Cunningham J, Armstrong BK. Long-term trends in cancer mortality for Indigenous Australians in the Northern Territory. Med J Aust 2004; 180: 504-507.

7 Liu B, Guthridge S, Li SQ, et al. The end of the Australia antigen? An ecological study of the impact of universal newborn hepatitis $B$ vaccination two decades on. Vaccine 2012; 30 : 7309-7314.

8 Carroll E, Page W, Davis JS. Screening for hepatitis B in East Arnhem Land: a high prevalence of chronic infection despite incomplete screening. Intern Med J 2010; 40 : 784-787.

9 Dent E, Selvey CE, Bell A, et al. Incomplete protection against hepatitis $B$ among remote Aboriginal adolescents despite full vaccination in infancy. Commun Dis Intell Q Rep 2010; 34: 435-439.

10 Wood N, Backhouse J, Gidding HF, et al. Estimates of chronic hepatitis B virus infection in the Northern Territory. Commun Dis Intell Q Rep 2005; 29: 289-290.

11 Graham S, Guy RJ, Cowie B, et al. Chronic hepatitis $B$ prevalence among Aboriginal and Torres Strait Islander Australians since universal vaccination: a systematic review and metaanalysis. BMC Infect Dis 2013; 13: 403.

12 MacLachlan JH, Allard N, Towell V, Cowie BC. The burden of chronic hepatitis B virus infection in Australia, 2011. Aust N Z J Public Health 2013; 37: 416-422.

13 Bruix J, Sherman M; Practice Guidelines Committee, American Association for the Study of Liver Diseases. Management of hepatocellular carcinoma. Hepatology 2005; 42: 1208-1236.

14 Chondur R, Guthridge S. Population data in the Northern Territory. Darwin: Department of Health and Community Services, 2006. http:// digitallibrary.health.nt.gov.au/prodjspui/ bitstream/10137/113/1/population_info_paper_ formatted_aug06.pdf (accessed Jan 2014).

15 Australian Bureau of Statistics. Australian demographic statistics, September quarter
2002. Canberra: ABS, 2003. (ABS Cat. No. 3101.0.) http://www.abs.gov.au/AUSSTATS/ subscriber.nsf/log?openagent\&31010_sep $\% 20$ 2002.pdf\&3101.0\&Publication\&104DE27A79 8E5A37CA256CEE008139E4\&24\&Sep\%20 2002\&20.03.2003\&Previous (accessed Feb 2014).

16 Mazzaferro V, Regalia E, Doci R, et al. Liver transplantation for the treatment of small hepatocellular carcinomas in patients with cirrhosis. N Engl J Med 1996; 334: 693-699.

17 Bruix J, Sherman M; American Association for the Study of Liver Diseases. Management of hepatocellular carcinoma: an update. Hepatology 2011; 53: 1020-1022.

18 European Association for the Study of the Liver, European Organisation for Research and Treatment of Cancer. EASL-EORTC clinical practice guidelines: management of hepatocellular carcinoma. J Hepatol 2012; 56: 908-943.

19 Zhang BH, Yang BH, Tang ZY. Randomized controlled trial of screening for hepatocellular carcinoma. J Cancer Res Clin Oncol 2004; 130: 417-422.

20 McMahon BJ, Bulkow LR, Singleton RJ, et al. Elimination of hepatocellular carcinoma and acute hepatitis $B$ in children 25 years after a hepatitis B newborn and catch-up immunization program. Hepatology 2011; 54 801-807.

21 Sun Z, Chen T, Thorgeirsson SS, et al. Dramatic reduction of liver cancer incidence in young adults: 28 year follow-up of etiological interventions in an endemic area of China. Carcinogenesis 2013; 34: 1800-1805.

22 Robotin MC, Kansil M, Howard K, et al. Antiviral therapy for hepatitis B-related liver cancer prevention is more cost-effective than cancer screening. J Hepatol 2009; 50: 990-998. 